\title{
Rheological Properties of HDPE and LDPE at the Low-Frequency Range Under Supercritical $\mathrm{CO}_{2}$
}

Chen Wan ${ }^{\mathrm{a}}$, Gangwei Sun ${ }^{\mathrm{b}}$, Tao Liu ${ }^{* a}$, Mohamed Esseghir ${ }^{*}$, Ling Zhao ${ }^{\mathrm{a}}$ and Weikang Yuan $^{\mathrm{a}}$

a: Shanghai Key Laboratory of Multiphase Materials Chemical Engineering, East China University of Science and Technology, Shanghai 200237, P. R. China.

b: Dow Chemical China Co Ltd, Elastomers, Electrical \& Telecommunications R\&D, Shanghai 201203, P. R. China.

c: Dow Chemical Company, Elastomers, Electrical \& Telecommunications R\&D, Collegeville, PA 19426, USA.

* Corresponding authors. Tel.: +86 21 64253470; fax: +86 2164253528.

Tel.: 610-244-7089; fax: 610-244-6144.

E-mail: liutao@ecust.edu.cn (T. Liu), esseghm@dow.com (M. Esseghir) 


\begin{abstract}
The effects of temperature, pressure (using helium as the pressurizing medium) and dissolved $\mathrm{CO}_{2}$ concentration on the rheological properties of linear high-density polyethylene (HDPE) and branched-chain low-density polyethylene (LDPE) were carefully investigated using a high-pressure rheometer. The results showed that at low pressure, the rheology of the PEs was sensitive to pressure increase. As the pressure increased to higher values, the rheology leveled off for HDPE and increased for LDPE. Under supercritical $\mathrm{CO}_{2}$, the plasticization of the dissolved gas contributed primarily to the thickening effect of pressure. Furthermore, the loss factors decreased with increasing pressure and increased with increasing $\mathrm{CO}_{2}$ pressure. Lastly, the effect of gas concentration was described by the Fujita-Kishimoto model on the assumption that the coupled effect of pressure and $\mathrm{CO}_{2}$ concentration could be separated.
\end{abstract}

Keywords: HDPE, LDPE, diffusion, high-pressure rheology, supercritical $\mathrm{CO}_{2}$ 


\section{Introduction}

As a green solvent, supercritical carbon dioxide $\left(\mathrm{scCO}_{2}\right)$ has found widespread use in polymer processing, including polymer blending [1], particle production [2], microcellular foaming [3, 4], polymer modification [5], polymerization [6] and polymer composites formation [7]. Dissolution of $\mathrm{scCO}_{2}$ into polymers leads to a decrease in their viscosity, melting point $\left(T_{\mathrm{m}}\right)$, crystallization temperature $\left(T_{\mathrm{c}}\right)$ and glass transition temperature $\left(T_{\mathrm{g}}\right)[3,8,9]$, which is beneficial to polymer processing operations, especially for polymers that are sensitive to temperature degradation, such as poly(lactic acid) (PLA). A good understanding of the rheological properties of the polymer/ $/ \mathrm{CO}_{2}$ solution is important to enable the design and optimization of $\mathrm{scCO}_{2}$-assisted polymer processing operations (e.g., polymer foaming). The rheological properties of the polymer and in particular the polymer/ $\mathrm{CO}_{2}$ solution, determine the flow behavior of the solution in the processing system, and therefore, cell generation and growth [10]. Most of the available literature has examined the rheological behavior under atmospheric conditions [11, 12]. However, the foaming process occurs under high pressure and in the presence of a blowing agent, which influences the rheological properties. Therefore, it would be more effective to characterize the rheological properties under typical foaming conditions to enable the design and optimization of the most effective foaming process.

However, determining the rheological properties of a polymer/ $\mathrm{CO}_{2}$ solution is challenging because the system requires high pressure to ensure the phase stability of the solution. Various devices have been designed and used to measure rheological 
properties under high pressure. Initially, capillary- and slit-die rheometers were utilized to characterize the dependence of the shear viscosity depression on the $\mathrm{CO}_{2}$ concentration in the polymer melt [13-16]. However, the dependence of the shear viscosity on pressure cannot be quantitatively characterized because the measurement itself is pressure-dependent. Indeed, a back pressure assembly must be mounted on the die to ensure that the measurement pressure is higher than the saturation pressure. The measurement is also a single-point test, and the shear rate is limited to the high shear region, which is approximately 100 1/s because the velocity of the polymer/gas solution in the die is relatively high. In addition, it has been reported that the so-called "pressure shift factor" discussed in the literature to describe the effect of pressure on the viscosity of polymer melts, which flow through a capillary or slit die, is based on an erroneous belief that there is a physically meaningful isotropic pressure that can be measured [17]. Therefore, the pressure-driven flow should be reconsidered when studying the rheological properties of polymer/gas solutions under high pressure.

Recent studies have focused on the modification and improvement of the rheometry technique to enable the use of small sample amounts in characterizing the dependence of shear viscosity on the temperature and shear rate. For example, the magnetic coupling used to drive the rheometer fixture and transfer the torque resolved the sealing issue $[18,19]$. Flichy et al. adopted vane geometries to substitute the concentric cylinder, which ensures good and relatively fast mixing [19]. However, the unconventional geometry must still be calibrated for viscosity measurements. The proposed approach is very useful for the characterization of low-viscosity Newtonian 
liquids; however, it is impractical for polymer/ $\mathrm{CO}_{2}$ solutions because a large torque is required for a magnetic coupling. A high-pressure sliding plate rheometer has also been developed to determine the effects of shear strain, temperature, pressure and gas concentration on the viscosity [20]. However, this device is not a commercially available instrument and its complex construction has limited its application.

In addition to the measuring device, the formation of the polymer/ $\mathrm{CO}_{2}$ solution has also hindered the progress of characterization techniques. Handge and Altstädt used two different procedures to saturate polystyrene (PS) with $\mathrm{CO}_{2}$ at temperatures higher or lower than its $T_{g}$ [21]. The results indicated that to a certain extent, the preloading procedure at temperatures below $T_{g}$ reduced the required saturation time. Tomasko et al. substituted a porous cup for a solid cup, which changed the axial diffusion to radial diffusion of $\mathrm{CO}_{2}$ through the porous wall and significantly reduced the diffusion distances [18]. However, the Couette geometry was not recommended for the rheological characterization of the polymer/ $\mathrm{CO}_{2}$ solution because the poor melt fluidity impeded the filling process and the geometry's large contact region limited the test range. Recently, researchers have been using a plate-plate geometry loaded in a high-pressure cell [21-23]. This configuration is beneficial for gas diffusion because the gap is just $1-2 \mathrm{~mm}$ and the sample can be easily cleaned. However, the gap cannot be adjusted as well as at the region where the shaft bearings are connected in the high-pressure chamber. Thus, the sample may not fully fill inside the gap, resulting in a large margin of error.

Nevertheless, researchers have conducted extensive studies on the rheology of 
polymer/gas solution by using a capillary or a slit die in a high-pressure rheometer arrangement. Aho and Syrjälä investigated the effect of pressure on the melt viscosity of five polymers using a modified capillary rheometer [24]. Their results indicated that amorphous polymers with a more complex molecular structure have larger pressure coefficients compared with semi-crystalline polymers. Dealy et al. investigated the influence of long-chain branching on time-pressure and time-temperature shift factors for PS and polyethylene (PE) [25]. Their results showed that long-chain branching affected neither the temperature nor the pressure shift factors in PS but had a strong effect on the PE shift factors. Unlike the thickening effect of pressure, gas dissolution causes plasticization of the melt. Park and Dealy found that $\mathrm{CO}_{2}$ and $\mathrm{N}_{2}$ had the same effect on viscosity if the concentration was expressed in moles and the shift factor for concentration alone could be separated from the coupled pressure and concentration [20]. Royer et al. applied the Williams-Landel-Ferry (WLF) equation to derive the effect of gas concentration on PS and polydimethylsiloxane (PDMS) at a test temperature of approximately $T_{g}$ $+100{ }^{\circ} \mathrm{C}[26,27]$. Further Raps used an analogous Arrhenius equation to describe the gas concentration shift factor for measurement temperatures higher than $T_{g}+100{ }^{\circ} \mathrm{C}$ [23].

The viscosity of a number of polymers, including PS, PDMS, polypropylene (PP), HDPE, LDPE, poly(propylene glycol) (PPG), poly(butylene succinate) (PBS) and PLA, has been studied under high pressure [19-21, 25-28]. However, few researchers have attempted to systematically analyze the effect of branched chains on 
viscosity using high-pressure rheology. In this work, linear HDPE and branched-chain LDPE were selected to study the effects of temperature, pressure and $\mathrm{CO}_{2}$ concentration on the rheological properties by using a high-pressure rheometer. Gas solubility and diffusivity were first characterized to estimate the diffusion time required for the dissolution of $\mathrm{CO}_{2}$ in the polymer melts. Subsequently, the effects of temperature, pressure and the combined pressure and gas concentration on the rheological properties were investigated. Moreover, the effect of gas concentration on the viscosity was isolated from the combined effects of pressure and gas concentration.

\section{Experimental}

\subsection{Materials and sample preparation}

The polymer resins, HDPE (DGDA-6944 NT) and LDPE (DFDB-1258 NT), used in this work are commercially available products provided by the Dow Chemical Company. Molecular characterization was performed using Polymer Laboratories 220 high temperature Size-Exclusion-Chromatography (SEC) with on-line differential refractive index (DRI), light scattering, and viscometer detectors. The results of the weight average molecular mass, $M_{w}$, Z-average molecular weight, $M_{z}$, polydispersity index, $M_{w} / M_{n}$ and melting index (MI) are listed in Table 1.

The resin pellets were dried under vacuum at $70{ }^{\circ} \mathrm{C}$ for 5 hours before the experiments. $\mathrm{CO}_{2}$ and helium (purity: $99.9 \%$, w/w \%) were obtained from Shanghai Woge Gases Inc.

Table 1 


\subsection{Rheological measurements}

Rheological measurements were performed by using a HAAKE MARS III rheometer with a high pressure D400/300 cell, which can withstand a maximum pressure and temperature of 400 bar and $300{ }^{\circ} \mathrm{C}$, respectively. Compared to a conventional rheometer equipped with parallel plates, cone plates or a coni-cylinder geometry, the high-pressure sensor system is comprised of a rotor and a stator. A schematic representation of the experimental setup is presented in Figure 1, with the geometrical size of the rotor also included. The rotor was supported and centered between two sapphire bearings. The torque acting on the rotor was transmitted from the drive of the rheometer with a magnetic clutch. The magnetic clutch makes use of two encapsulated ring-magnets separated by a stainless steel diaphragm in the cover flange. The lower magnet is attached to the rotor. The outer magnet is encapsulated in a part, which is fitted with the conical bore to allow its connection to the drive shaft of the HAAKE rheometer. The gap between the rotor and the stator must be completely filled with the test sample [29].

The mass of the polymer melt used in this work was calculated using the density determined under high temperature and pressure, as shown in Table 1. By considering that the torque only varies from 0.6 to $200 \mathrm{mNm}$ and to inhibit the Weissenberg effect during the strong shear process, the measured viscosity primarily comes from the dynamic frequency sweep test rather than the strong shear process. In this work, the dynamic frequency test was conducted under a controlled stress of $100 \mathrm{~Pa}$ within the linear viscoelastic range. Supercritical $\mathrm{CO}_{2}$ is delivered into the cell via a TELIDE 
S-486-JN-60 pump, which can deliver a maximum pressure of $42 \mathrm{MPa}$. Before the test, low-pressure $\mathrm{CO}_{2}$ was injected into the chamber 3 times to purge the air in the system and reduce potential oxygen-induced degradation of the sample. The dynamic oscillatory viscoelasticity was correlated with steady shear properties using the Cox-Merz rule. The Cross model, expressed as Eq. (1), was applied to fit the results.

$$
\eta(\dot{\gamma})=\eta_{0} /\left(1+(\lambda \dot{\gamma})^{n}\right)
$$

where $\eta(\dot{\gamma})$ is the steady shear viscosity in Pa.s, $\eta_{0}$ is the zero-shear viscosity in Pa.s, $\dot{\gamma}$ is the shear rate in $1 / \mathrm{s}, \lambda$ is the relaxation time in s, and $n$ is the Cross exponent. The shift factors were calculated as the ratio between the zero-shear viscosity of the experimental and reference samples.

\section{Figure 1}

According to the diffusion distance (indicated by the red arrow in Figure 1) and the gas diffusivity, the gas saturation is set at 12 hours. Since the gas diffusion coefficient was measured under a state, a small-amplitude oscillatory shear was found to significantly accelerate the diffusion process [20]. Thus, the saturation time is sufficient for achieving dissolution equilibrium in the test area. It should be noted that a certain level of pressure must be applied on the sample especially for the first test process, which was assumed to be a diluent-free system since it is difficult for the polymer to thoroughly fill the gap under gravity alone. Here, a pressure of nearly 1 $\mathrm{MPa}$ was exerted to force the polymer melt to fill the gap while maintaining a negligible effect of the diluent content.

\section{Results and discussion}




\subsection{Feasibility analysis of the measurement}

In this work, the feasibility analysis involved examination of the sample stability and experimental data reliability. The saturation time took as long as 38 hours for several saturation processes to generate a homogeneous polymer/ $\mathrm{CO}_{2}$ solution around the rotor at high temperature. Table 1 shows the molecular parameters of the polymer raw material and following the saturation process. The results show that the molecular mass didn't show much difference, indicating the degradation was negligible even at the highest test temperature. The degradation for the other tests should be smaller because relatively lower temperature are employed.

It is necessary to characterize the experimental data reliability when the rotor is not directly connected to the rheometer but is driven through magnetic interaction in a non-contact manner. The transducer response, which is closely related to the sample, may involve artefacts at both the high- and low-frequency ranges [30]. Thus, the test feasibility was investigated by comparing the results of a shaft-driven plate and the magnetic-driven rotor. Figure 2 shows the rheological test results of the plate and rotor from a dynamic frequency sweep test of the two polymers. At the low-frequency range, the polymer viscosity obtained for the rotor is slightly higher than that for the plate; this is caused by the frictional resistance of the sapphire bearings compared with that of the shaft bearings. Moreover, a pressure (of $1 \mathrm{MPa}$ ) is exerted on the polymer in the rotor configuration. At the high-frequency range, mechanical delays may overlap the signal response from the sample, which results in a large error. In this work, the focus is on the zero-shear viscosity that is correlated with the low-frequency 
range. Thus, it is feasible to use this method to characterize the viscosity in a high-pressure chamber given the small error in the low-frequency range.

Figure 2

\subsection{Effect of temperature on the viscosity at atmospheric pressure}

The effect of temperature on viscosity has been widely investigated using a conventional rheometer [31-34]. Although the plate geometry may lead to more accurate results, the rotor was selected in the high pressure chamber for the viscosity test in this work to maintain consistency with the geometry used in the latter characterization. Figure 2 shows typical plots of frequency dependence of the complex viscosity and modulus of HDPE and LDPE at $150{ }^{\circ} \mathrm{C}$. For HDPE, a plateau region exists at the low-frequency region, in which the viscosity is independent of frequency, and therefore, the polymer behaves as a Newtonian fluid. However, a decreasing viscosity is observed as the frequency increases, which is indicative of shear-shinning behavior. For LDPE, the long and entangled polymer chains become unraveled and drawn out in the direction of shear as the rotor begins to rotate. Therefore, the viscosity is found to decrease, which indicates a shear-shinning behavior in all the regions $[22,35]$. Figure 3 shows the temperature shift factors and the Arrhenius (Eq. (2)) fitting results using least square method for the two polymers:

$$
\ln \left(a_{T}\right)=\frac{E_{a}}{R}\left(\frac{1}{T}-\frac{1}{T_{r}}\right)
$$

where $a_{T}$ is the temperature shift factor, $E_{a}$ is the activation energy for flow in $\mathrm{kJ} / \mathrm{mol}$, $T_{r}$ is the reference temperature in Kelvin and $R$ is the gas constant. One can also envision the viscosity of the two polymers to decrease as the temperature is increased. 
Indeed, more energy is supplied to the chains as the increases. This results in an increase in their mobility and an increase in the free volume fraction, consequently, the viscosity is reduced. The activation energy of LDPE is slightly higher than that of HDPE, which is also consistent with literature reports.

\section{Figure 3}

\subsection{Effect of pressure on the rheological properties}

The importance of pressure dependence of the melt viscosity, especially in the injection molding or extrusion foaming process, has been widely recognized. Any increase in viscosity will result in higher viscous heat dissipation, which may have undesirable effects on the process. According to Henry's Law, the gas content in the polymer is correlated with the gas pressure. Therefore, helium, an insoluble gas in the polymer, is used to exert pressure while retaining a diluent-free polymer [36]. In this work, the saturation process lasts for 30 minutes when helium is used to characterize the dependence of the rheological properties on pressure.

The original complex viscosity data are shown in Figure S3. Table 2 displays the typical curve fitting results of the two polymers using the Cross model at different pressures and a temperature of $150{ }^{\circ} \mathrm{C}$. The results for LDPE clearly show an increase in the zero-shear viscosity and relaxation time as the pressure increases. This result can be attributed to the free volume compression, which resulted from the increase in pressure that hindered chain mobility and relaxation. For HDPE, the zero-shear viscosity and the relaxation time are found to first increase at low pressure and then level off at high pressure. A possible explanation for this behavior will be explored 
below. The Cross exponent, which is closely related to the polymers themselves, doesn't not differ much; in other words, the pressure has virtually no effect on the mechanism of chains mobility.

\section{Table 2}

The Barus equation [37] was used to determine the relationship between pressure and viscosity, as shown in Eq. (3):

$$
\ln \left(a_{P}\right)=\beta\left(P-P_{r}\right)
$$

where $a_{p}$ is the pressure shift factor, $\beta$ is the pressure coefficient in $1 / \mathrm{GPa}, P$ is the system pressure in $\mathrm{MPa}$, and $P_{r}$ is the reference pressure in $\mathrm{MPa}$.

Figure 4 shows the pressure shift factors based on the curve fitting results at different temperatures. The trends for the viscosity variation at different temperatures, depending on the pressure, have previously been illustrated. For HDPE, the curve fitting was divided into two parts to enable a better understanding of the mechanism. The pressure coefficients are much higher at pressures below $10 \mathrm{MPa}$ compared to those at pressures above $10 \mathrm{MPa}$. For LDPE, the pressure coefficients maintain a high value and do not show any turning -points. At low pressure, the high values of the free volume fractions of both polymers increase the polymer chains mobility. From a macroscopic view, both polymers are sensitive to the effect of pressure. At high pressure, the turning-points for HDPE can be attributed to the relatively small free volume fraction compared with LDPE [38]. At high pressure, such as above $10 \mathrm{MPa}$, the polymer chains grow closer and the free volume is compressed, resulting in a higher chain entanglement density for HDPE; in addition, the highly entangled chains 
are insensitive to an increase in pressure. It should be noted that for branched and linear PS, the free volume might be not susceptible to the pressure change, because the temperature dominant the process, resulting in little difference of the pressure shift factor of the two polymers $[24,25]$. From a macroscopic perspective, the plateau region at high pressure shown in Figure 4 indicates the insensitivity. However, the branched chains provide a relatively large fractional free volume for LDPE, which would provide more freedom for the chains to move; consequently, the polymer chains remain sensitive to an increase in pressure at high pressures.

\section{Figure 4}

\section{Table 3}

The pressure coefficient of LDPE does not show a significant change with pressure, and the coefficients are between $20-26 \mathrm{GPa}^{-1}$ at $170{ }^{\circ} \mathrm{C}$, as was previously reported [25]. For HDPE, however, there is significant deviation between the results of this work and previous literature for the coefficient of $15 \mathrm{GPa}^{-1}$ obtained at $180{ }^{\circ} \mathrm{C}$. The reason for this is primarily attributed to two aspects: one is the differences in molecular parameters and test conditions, including the temperature and the high pressure exerted approach [20]. The other difference is the introduction of the turning-point concept, which, to the authors' knowledge, is being reported here for the first time. Although inappropriate, the pressure coefficients would likely be similar if the curve fitting was entirely considered.

Another notable point is that there are opposite trends in the variation of the pressure coefficients for both polymers, as shown in Table 3. Indeed, the pressure 
coefficients decreased as the temperature increases for HDPE, while the opposite is observed for LDPE. In particular, the coefficient is closely related to the free volume fraction. When a polymer is heated under high pressure, two competing factors emerge. First, more energy is supplied to the chains with increasing temperature, resulting in a higher free volume, (i.e., higher mobility), and consequently, a reduced viscosity. In addition, high pressure leads to compression of the free volume, that is, it prevents the viscosity from decreasing. From the experimental results, it can be inferred that, the increase in free volume for LDPE, as a result of increased temperature, would outweigh the pressure effect.

The raw data for the modulus at different temperatures and pressures are shown in Figure S4. Here, only a range from 0.1 to $10 \mathrm{rad} / \mathrm{s}$ is plotted in the figures, as a high-frequency range may introduce unacceptably high errors. The variation trends of the modulus are analogous to those of the viscosity because the increased pressure compresses the free volume and restricts the movement of the polymer chains. Clearly, the modulus increases with increasing pressure. A plateau in $\mathrm{G}^{\prime}$ is observed at high frequencies as the material becomes inflexible and rigid under a strong sweep test. Figure 5 shows the loss factors (i.e., the ratio of loss modulus to storage modulus) of HDPE and LDPE at different pressures. The loss factors decreased with increasing pressure; indicating that the storage modulus is more sensitive to the pressure compared to the loss modulus, that is, G' increased more quickly than G' as the pressure increases.

\section{Figure 5}




\subsection{Combined effects of pressure and $\mathrm{CO}_{2}$ concentration on the rheological properties}

It is not possible to fully study the effect of $\mathrm{CO}_{2}$ concentration without considering the experimental pressure effect on the viscosity from the experiments. By using the gas diffusivity or confirming the invariability of the viscosity with time, both can be used to estimate the saturation time required. Initially, the saturation time was estimated. Then, the viscosity behavior was studied to confirm the saturation process during the experiment. The combined effects of pressure and $\mathrm{CO}_{2}$ content on the shift factors at $150{ }^{\circ} \mathrm{C}$ are shown in Figure 6. The original viscosity of the two polymers can be found in Figure S5.

\section{Figure 6}

The results clearly show that the viscosity decreases as the $\mathrm{CO}_{2}$ content increases. indicating that the plasticization effect of $\mathrm{scCO}_{2}$ outweighs the thickening effect of pressure. The gas that penetrated into the polymers weakens the intermolecular interactions, leading to a reduction in the viscosity [39]. Compared to the effect of the helium pressure, the competition here is between the pressure and concentration in the presence of $\mathrm{scCO}_{2}$. First, the pressure forces the polymer chains closer together, which hindered the chains' mobility and resulting in an increase in the modulus. In addition, the free volume increases because of the dissolution of $\mathrm{scCO}_{2}$ and subsequent swelling of the polymer, leading to an increase in chain mobility and thus, a reduction in the modulus. The variation in the viscosity and modulus indicates that 
the free volume increases as $\mathrm{CO}_{2}$ dissolution dominates, which results in a reduction observed in both the viscosity and modulus. Comparing previous literature and present results, the plasticization effect of gas dominates the process and the thinning behavior becomes more obvious as the $\mathrm{CO}_{2}$ pressure increases.

Figure 7 shows the loss factors of the two polymers at different $\mathrm{CO}_{2}$ pressures. In contrast with the pressure effect, the combined effect of $\mathrm{CO}_{2}$ pressure and concentration leads to opposite results. The loss factors increases with higher $\mathrm{CO}_{2}$ pressures and concentration. In the previous section, it was shown that the pressure exerts a negative effect on the loss factors. Thus, it is reasonable to assume that the $\mathrm{CO}_{2}$ concentration dominates the process, and that the gas plasticization effect primarily influences the storage modulus.

In general, a foaming process involves three important steps: cell nucleation, bubble growth and bubble coalescence [40-42]. There is no doubt that viscoelastic properties play a large role in the process. Park and Malone proposed a foamability factor $F=\rho D(\tan \delta)^{0.75} \leq 1.8$ to evaluate polymer melt foamability, in which $\rho$ is the density and $D$ is the cell diameter [43]. Apparently, maintaining the loss factor, $\tan \delta$, at a low value is beneficial to the foaming process. However, $\mathrm{CO}_{2}$ dissolution under high pressure would have two unfavorable effects: a plasticization effect, which results in pressure reduction in the extruder; and an increase in the loss factor, which gives rise to increases in the foamability factor. Pressure reduction, coupled with a decrease in the pressure-drop rate, negatively affects bubble nucleation. An increase in the loss factor indicates that the reduction in the storage modulus is more severe than 
that of the loss modulus, which itself is adverse to bubble growth. Thus, it has been recommended that, the $\mathrm{CO}_{2}$ concentration should not be too high below the solubility level for a foaming process.

\section{Figure 7}

\subsection{Effect of $\mathrm{CO}_{2}$ concentration on the rheological properties}

The dependence of temperature and pressure on the viscosity of a polymer has been widely investigated because these factors can be controlled separately. However, the effect of $\mathrm{CO}_{2}$ concentration is linked to pressure. Moreover, the gas concentration at saturation condition is not a crucial factor because the critical value is unsteady for practical applications. On the contrary, the dependence of viscosity on the $\mathrm{CO}_{2}$ concentration below the solubility level is extremely important for rheology investigations. To study the effect of gas concentration without considering pressure effect, the coupled effect of pressure and $\mathrm{CO}_{2}$ concentration was presumed to be separated:

$$
a(C)=a(P, C) / a(P)
$$

Where $a(P)$ was resulting from Eq. 3 and Fig. 6. The Fujita-Kishimoto (F-K) model, Eq. (5), was used to describe the effect of only the gas concentration on the viscosity variation [44].

$$
\ln a(C)=\frac{(-1 / f) C}{f / \theta+C}
$$

where $C$ is the gas concentration, $f$ is the fractional free volume, and $\theta$ is the contribution of the dissolved gas to the free volume increase. The plots of $\ln \left(a_{c}\right)$ 
versus $C$ are shown in Figure 8. The data was fitted using least square method and the results are shown in Table 4. It is clear that the gas concentration shift factor decreases as more $\mathrm{scCO}_{2}$ dissolves into the polymer. One point should be noted; the first saturation step with a pressure of $1 \mathrm{MPa}$, was used to compress the melt to fill the chamber, which was assumed to be diluent-free.

\section{Figure 8}

\subsection{Temperature-gas concentration conversion}

It is of interest to compare the plasticization effects of both the $\mathrm{CO}_{2}$ concentration and temperature because they are potentially vulnerable to degradation at high temperature during the processing state. Figure 9 shows the temperature, $\mathrm{CO}_{2}$ concentration and pressure shifting curves. Irrespective of the effect of pressure and the solubility, the plasticization effect for LDPE is equivalent for a temperature increase of $20{ }^{\circ} \mathrm{C}$ or an approximately $3 \%$ (wt/wt) $\mathrm{CO}_{2}$ dissolution. However, the dissolution of $\mathrm{CO}_{2}$ into $\mathrm{HDPE}$ to achieve a substantial reduction in the viscosity would be unsuccessful because the viscosity is not sensitive to relatively higher values of the pressure and gas concentration. It is convenient to calculate the shift factor $a=a(T) \cdot a(C) \cdot a(P)$, as shown in Eq. (6), from the legend assisted by their solubilities from the equations presented above. In particular, the results require further verification especially in the high-pressure range.

$$
a=\exp \left(\frac{E_{a}}{R}\left(\frac{1}{T}-\frac{1}{T_{r}}\right)+\beta\left(P-P_{r}\right)+\frac{(-1 / f) C}{f / \theta+C}\right)
$$

\section{Table 4}

Figure 9 
In Figure 10, the experiment was designed to check the validity of Equation 9. First, the sample was saturated using $\mathrm{CO}_{2}$ under pressure of $8 \mathrm{MPa}$ at $160{ }^{\circ} \mathrm{C}$, and then the pressure was increased by pumping helium to $12 \mathrm{MPa}, 16 \mathrm{MPa}$ and $20 \mathrm{MPa}$. The viscosity was characterized and the pressure shift factor was calculated. Thus, the gas concentration was fixed at $8 \mathrm{MPa}$ while pressure transformed. It can be seen that the developed model can estimate viscosity reduction of $\mathrm{PE} / \mathrm{CO}_{2}$ solution.

\section{Figure 10}

\section{Conclusion}

In this work, the effects of temperature, pressure and $\mathrm{CO}_{2}$ concentration on the rheological properties of linear HDPE and branched-chain LDPE were carefully investigated using a high-pressure rheometer. The effect of pressure on the rheology was determined using helium, an insoluble gas, as the pressurizing medium. The pressure shift factor (i.e., the ratio between the zero-shear viscosity of the experimental and reference samples) was fitted using the Barus equation. It was found that at low pressure $(<10 \mathrm{MPa})$, the rheological properties of the two polymers, including the complex viscosity, storage and loss modulus, were sensitive to pressure increase. As the pressure increased to a higher value, the rheology leveled off for HDPE, whereas a positive correlation remained for LDPE. In other words, a turning-point exists for the rheology of HDPE, which to the authors' knowledge, is a concept introduced here for the first time. This phenomenon can be attributed to the branched chains providing a relatively larger free volume fraction for the rheology improvement for LDPE. Furthermore, the loss factor decreased as the pressure 
increased, which indicates that the storage modulus was more sensitive to the pressure than the loss modulus. The combined effect of $\mathrm{CO}_{2}$ pressure and its concentration on the rheology was investigated after gas saturation of more than 12 hours to ensure the thorough dissolution of the gas into the polymer. Compared to the thickening effect of pressure, the plasticization effect of dissolved gas had a predominant influence on the polymer rheology. By analyzing the variation of the loss factors, it was observed that the storage modulus was more sensitive than the loss modulus to both the pressure and gas concentration. Comparing the loss factor variations under high-pressure conditions of $\mathrm{He}$ and $\mathrm{scCO}_{2}$, it is recommended that, the die pressure should be maintained at a higher value with the inclusion of as small an amount of $\mathrm{CO}_{2}$ as possible to enable better cell nucleation and bubble growth during the foaming extrusion process. Finally, the effects of the gas concentration and pressure were assumed to be separated, and the F-K model was used to clarify the effect of gas concentration on the viscosity. On the basis of these assumptions, a model was proposed that systematically describes the effects of the temperature-pressure-gas content.

\section{Acknowledgements}

This work was supported by the National Key Research and Development Program of China (2016YFB0302204) and the National Science Foundation of China (21376087). 


\section{References}

[1] J. DeFelice, J.E. Lipson, Polymer Miscibility in Supercritical Carbon Dioxide: Free Volume as a Driving Force, Macromolecules, 47 (2014) 5643-5654.

[2] S.-D. Yeo, E. Kiran, Formation of polymer particles with supercritical fluids: a review, J. Supercrit. Fluids, 34 (2005) 287-308.

[3] D.-C. Li, T. Liu, L. Zhao, W.-K. Yuan, Foaming of linear isotactic polypropylene based on its non-isothermal crystallization behaviors under compressed $\mathrm{CO}_{2}$, J. Supercrit. Fluids, 60 (2011) 89-97.

[4] A. Rizvi, A. Tabatabaei, M.R. Barzegari, S.H. Mahmood, C.B. Park, In situ fibrillation of $\mathrm{CO}_{2}$-philic polymers: Sustainable route to polymer foams in a continuous process, Polymer, 54 (2013) 4645-4652.

[5] T. Xia, Y. Feng, Y. Zhang, Z. Xi, T. Liu, L. Zhao, Novel Strategy for Polycondensation of Poly (ethylene terephthalate) Assisted by Supercritical Carbon Dioxide, Ind. Eng. Chem. Res., 53 (2014) 18194-18201.

[6] Y. Hwang, J. Jung, M. Ree, H. Kim, Terpolymerization of $\mathrm{CO}_{2}$ with propylene oxide and $\varepsilon$-caprolactone using zinc glutarate catalyst, Macromolecules, 36 (2003) 8210-8212.

[7] H. Ohde, M. Ohde, C.M. Wai, Swelled plastics in supercritical $\mathrm{CO}_{2}$ as media for stabilization of metal nanoparticles and for catalytic hydrogenation, Chem. Commun., (2004) 930-931.

[8] C.A. Kelly, S.M. Howdle, K.M. Shakesheff, M.J. Jenkins, G.A. Leeke, Viscosity studies of poly (DL - lactic acid) in supercritical $\mathrm{CO}_{2}$, J. Polym. Sci., Part B: Polym. 
Phys., 50 (2012) 1383-1393.

[9] S. Curia, D. De Focatiis, S. Howdle, High-pressure rheological analysis of $\mathrm{CO}_{2}$-induced melting point depression and viscosity reduction of poly ( $\varepsilon$-caprolactone), Polymer, 69 (2015) 17-24.

[10] J. Wang, W. Zhu, H. Zhang, C.B. Park, Continuous processing of low-density, microcellular poly(lactic acid) foams with controlled cell morphology and crystallinity, Chem. Eng. Sci., 75 (2012) 390-399.

[11] S. Li, M. Xiao, Y. Guan, D. Wei, H. Xiao, A. Zheng, A novel strategy for the preparation of long chain branching polypropylene and the investigation on foamability and rheology, Eur. Polym. J., 48 (2012) 362-371.

[12] A. Rizvi, A. Tabatabaei, M.R. Barzegari, S.H. Mahmood, C.B. Park, In situ fibrillation of $\mathrm{CO}_{2}$-philic polymers: Sustainable route to polymer foams in a continuous process, Polymer, 54 (2013) 4645-4652.

[13] C.D. Han, C.Y. Ma, Rheological properties of mixtures of molten polymer and fluorocarbon blowing agent. I. Mixtures of low - density polyethylene and fluorocarbon blowing agent, J. Appl. Polym. Sci., 28 (1983) 831-850.

[14] C.D. Han, C.Y. Ma, Rheological properties of mixtures of molten polymer and fluorocarbon blowing agent. II. Mixtures of polystyrene and fluorocarbon blowing agent, J. Appl. Polym. Sci., 28 (1983) 851-860.

[15] M. Nobelen, S. Hoppe, C. Fonteixa, F. Pla, M. Dupire, B. Jacques, Modeling of the rheological behavior of polyethylene/supercritical $\mathrm{CO}_{2}$ solutions, Chem. Eng. Sci., 61 (2006) 5334-5345. 
[16] S. Areerat, T. Nagata, M. Ohshima, Measurement and prediction of LDPE/CO solution viscosity, Polymer Engineering And Science, 42 (2002) 2234-2245.

[17] C.D. Han, What is the role of "pressure" in the use of capillary and slit flows to determine the shear-rate dependent viscosity of a viscoelastic fluid?, Polym. Eng. Sci., 48 (2008) 1126-1140.

[18] M.J. Wingert, S. Shukla, K.W. Koelling, D.L. Tomasko, L.J. Lee, Shear viscosity of $\mathrm{CO}_{2}$-plasticized polystyrene under high static pressures, Ind. Eng. Chem. Res., 48 (2009) 5460-5471.

[19] N. Flichy, C. Lawrence, S. Kazarian, Rheology of poly (propylene glycol) and suspensions of fumed silica in poly (propylene glycol) under high-pressure $\mathrm{CO}_{2}$, Ind. Eng. Chem. Res., 42 (2003) 6310-6319.

[20] H.E. Park, J.M. Dealy, Effects of pressure and supercritical fluids on the viscosity of polyethylene, Macromolecules, 39 (2006) 5438-5452.

[21] U.A. Handge, V. Altstädt, Viscoelastic properties of solutions of polystyrene melts and carbon dioxide: Analysis of a transient shear rheology approach, Journal of Rheology (1978-present), 56 (2012) 743-766.

[22] C.A. Kelly, S.H. Murphy, G.A. Leeke, S.M. Howdle, K.M. Shakesheff, M.J. Jenkins, Rheological studies of polycaprolactone in supercritical $\mathrm{CO}_{2}$, Eur. Polym. J., 49 (2013) 464-470.

[23] D. Raps, T. Köppl, A.R. de Anda, V. Altstädt, Rheological and crystallisation behaviour of high melt strength polypropylene under gas-loading, Polymer, 55 (2014) $1537-1545$. 
[24] J. Aho, S. Syrjälä, Measurement of the pressure dependence of viscosity of polymer melts using a back pressure - regulated capillary rheometer, J. Appl. Polym. Sci., 117 (2010) 1076-1084.

[25] H.E. Park, J. Dealy, H. Münstedt, Influence of long-chain branching on time-pressure and time-temperature shift factors for polystyrene and polyethylene, Rheol. Acta, 46 (2006) 153-159.

[26] J.R. Royer, J.M. DeSimone, S.A. Khan, High - pressure rheology and viscoelastic scaling predictions of polymer melts containing liquid and supercritical carbon dioxide, J. Polym. Sci., Part B: Polym. Phys., 39 (2001) 3055-3066.

[27] J.R. Royer, Y.J. Gay, J.M. Desimone, S.A. Khan, High - pressure rheology of polystyrene melts plasticized with $\mathrm{CO}_{2}$ : Experimental measurement and predictive scaling relationships, J. Polym. Sci., Part B: Polym. Phys., 38 (2000) 3168-3180.

[28] D. Ladin, C.B. Park, S.S. Park, H.E. Naguib, S.W. Cha, Study of shear and extensional viscosities of biodegradable PBS/CO $\mathrm{CO}_{2}$ solutions, J. Cell. Plast., 37 (2001) 109-148.

[29] ThermoFisher, Instruction Manual, HAAKE Pressure Cell D400/300, Version 2.0, (2012) 9-13.

[30] S. Ouchi, Y. Masubuchi, H. Shikuma, The effect of $\mathrm{CO}_{2}$ pressure on viscoelasticity of LDPE, Int. Polym. Proc., 23 (2008) 173-177.

[31] J.M. Dennis, J.S. Enokida, T.E. Long, Synthesis and Characterization of Decahydronaphthalene-Containing Polyesters, Macromolecules, $48 \quad$ (2015) 8733-8737. 
[32] C.R. López-Barrón, P. Brant, A.P. Eberle, D.J. Crowther, Linear rheology and structure of molecular bottlebrushes with short side chains, Journal of Rheology (1978-present), 59 (2015) 865-883.

[33] K. Rinawa, S. Maiti, R. Sonnier, J.-M.L. Cuesta, Dynamic rheological studies and applicability of time-temperature superposition principle for PA12/SEBS-g-MA blends, Polym. Bull., 72 (2015) 3305-3324.

[34] M. Hu, Y. Xia, C.S. Daeffler, J. Wang, G.B. McKenna, J.A. Kornfield, R.H. Grubbs, The linear rheological responses of wedge - type polymers, J. Polym. Sci., Part B: Polym. Phys., 53 (2015) 899-906.

[35] Osswald T, Hernandez-Oritz JP, Polymer processing: Modeling and Simulation, Ohio, US: Hanser Garden Publications Inc, 2006.

[36] A. Wong, S.N. Leung, M.M. Hasan, C.B. Park, The foamability of polypropylene copolymer blown with argon, nitrogen and helium, in: Society of Plastic Engineeers Annucal Technical Conference, Milwaukee, 2008, pp. 2534-2538.

[37] C. Barus, Note on the Dependence of Viscosity on Pressure and Temperature, Proc. Am. Acad. Arts Sci, 27 (1891) 13-18.

[38] A.K. Doolittle, Studies in Newtonian flow. II. The dependence of the viscosity of liquids on free - space, J. Appl. Phys., 22 (1951) 1471-1475.

[39] S.G. Kazarian, M.F. Vincent, F.V. Bright, C.L. Liotta, C.A. Eckert, Specific intermolecular interaction of carbon dioxide with polymers, J. Am. Chem. Soc., 118 (1996) 1729-1736.

[40] L. Shau-Tarng, Foam Nucleation in Gas-Dispersed Polymeric Systems, in: 
Foam Extrusion, CRC Press, 2014, pp. 165-212.

[41] G. Richard, E.D. Louis, Rheology of Thermoplastic Foam Extrusion Process, in: Foam Extrusion, CRC Press, 2014, pp. 39-82.

[42] N.S. Ramesh, Foam Growth in Polymers, in: Foam Extrusion, CRC Press, 2014, pp. 213-238.

[43] C.P. Park, B.A. Malone, Extruded closed-cell polypropylene foam, in, Google Patents, 1996.

[44] H. Fujita, A. Kishimoto, Diffusion-controlled stress relaxation in polymers. II. Stress relaxation in swollen polymers, J. Polym. Sci., 28 (1958) 547-567. 


\section{Captions}

Figure 1. Schematic of high-pressure attachment for the rheometer, which consists of a magnetic clutch, a pressure cell, a rotor and a stator (dimensions in $\mathrm{mm}$ ).

Figure 2. Comparison of the experimental results between the plate geometry (solid interior) and rotor geometry (open interior) configurations of (a) HDPE and (b) LDPE at $150{ }^{\circ} \mathrm{C}$, including $\eta^{*}(\mathbf{\bullet}, \square), \mathrm{G}^{\prime}(\boldsymbol{\Delta}, \Delta)$ and $\mathrm{G}^{\prime \prime}(\diamond, \diamond)$.

Figure 3. Temperature shift factors of the two polymers and the Arrhenius fitting results. The lines are the model fitting values, and symbols represent the experimental results for HDPE $(\square,-)$ ) and LDPE $(\boldsymbol{\Lambda},---)$. The reference temperature $T_{r}=150{ }^{\circ} \mathrm{C}, E_{a, H D P E}=26.63 \pm 0.35 \mathrm{~kJ} / \mathrm{mol}$ and $E_{a, L D P E}=37.52$ $\pm 1.27 \mathrm{~kJ} / \mathrm{mol}$.

Figure 4. Effect of helium pressure on the pressure shift factors at different temperature. The reference temperature $T_{r}=150{ }^{\circ} \mathrm{C}$, and the reference pressure $P_{r}=1.0 \mathrm{MPa}$. The lines are model fitted values, and symbols are the experimental results for (a) HDPE and (b) LDPE at $150{ }^{\circ} \mathrm{C}(\square,-$ ), $160{ }^{\circ} \mathrm{C}(\bullet,---), 170{ }^{\circ} \mathrm{C}(\Delta, \cdots)$ and $180^{\circ} \mathrm{C}(\boldsymbol{\nabla},---)$.

Figure 5. Effect of helium pressure on the loss factors of HDPE and LDPE at $150{ }^{\circ} \mathrm{C}$. (a) HDPE: $1.01 \mathrm{MPa}(\square), 4.98 \mathrm{MPa}(\boldsymbol{\Delta}), 9.34 \mathrm{MPa}(\diamond), 15.59 \mathrm{MPa}(\triangleright)$, and $20.46 \mathrm{MPa}(\nabla)$; (b) LDPE: $1.02 \mathrm{MPa}(\square), 5.81 \mathrm{MPa}(\boldsymbol{\Delta}), 10.80 \mathrm{MPa}$ $(\diamond), 15.06 \mathrm{MPa}(\triangleright)$ and $19.61 \mathrm{MPa}(\nabla)$.

Figure 6. Combined effects of $\mathrm{CO}_{2}$ content and pressure on the shift factors of (a) HDPE and (b) LDPE at different temperatures: $150{ }^{\circ} \mathrm{C}(\square), 160{ }^{\circ} \mathrm{C}(\bullet)$, $170{ }^{\circ} \mathrm{C}(\Delta)$, and $180{ }^{\circ} \mathrm{C}(\boldsymbol{\nabla})$.

Figure 7. Combined effect of $\mathrm{CO}_{2}$ pressure and concentration on the loss factors of (a) HDPE: $1.07 \mathrm{MPa}(\square), 6.13 \mathrm{MPa}(\boldsymbol{\Delta}), 17.22 \mathrm{MPa}(\diamond), 25.67 \mathrm{MPa}(\boldsymbol{\nabla})$ and (b) LDPE: $1.09 \mathrm{MPa}(\square), 5.36 \mathrm{MPa}(\boldsymbol{\Delta}), 16.56 \mathrm{MPa}(\diamond), 22.77 \mathrm{MPa}(\boldsymbol{\nabla})$ at $150{ }^{\circ} \mathrm{C}$.

Figure 8. Effect of $\mathrm{CO}_{2}$ concentration on the gas concentration shift factors for (a) HDPE and (b) LDPE. The lines are model fitted values, and symbols are the experimental results at $150{ }^{\circ} \mathrm{C}(\square,-),, 160{ }^{\circ} \mathrm{C}(\bullet,---), 170{ }^{\circ} \mathrm{C}(\Delta, \cdots)$ and $180{ }^{\circ} \mathrm{C}(\boldsymbol{\nabla},---)$.

Figure 9. Effect of (a) temperature $\left(\boldsymbol{T},{ }^{\circ} \mathrm{C}\right)$, (b) $\mathrm{CO}_{2}$ concentration $(\boldsymbol{C}, \mathrm{g}$ gas $/ \mathrm{g}$ polymer) and (c) pressure $(\boldsymbol{P}, \mathrm{MPa})$ on the rheological shift factors of $\operatorname{HDPE}(-)$ and LDPE (---).

Figure 10. Comparison of experimental results with the model (Eq. (9)) fitting results of HDPE and LDPE. The lines are the model fitting values, and symbols represent the experimental results for $\operatorname{HDPE}(\square,-)$ and $\operatorname{LDPE}(\boldsymbol{\Delta},---)$.

Table 1. Molecular parameters and thermal properties of HDPE and LDPE from SEC 
Table 2. Calculation of the zero-shear viscosity, relaxation time and Cross exponent for HDPE and LDPE at $150{ }^{\circ} \mathrm{C}$ under different pressures. The reference temperature $T_{r}=150{ }^{\circ} \mathrm{C}$, and the reference pressure $P_{r}=1.0 \mathrm{MPa}$.

Table 3. Pressure coefficients of HDPE and LDPE.

Table 4. Fitting parameters for the dependence of viscosity on the temperature, pressure and $\mathrm{CO}_{2}$ concentration of HDPE and LDPE. 


\section{Figures and Tables}

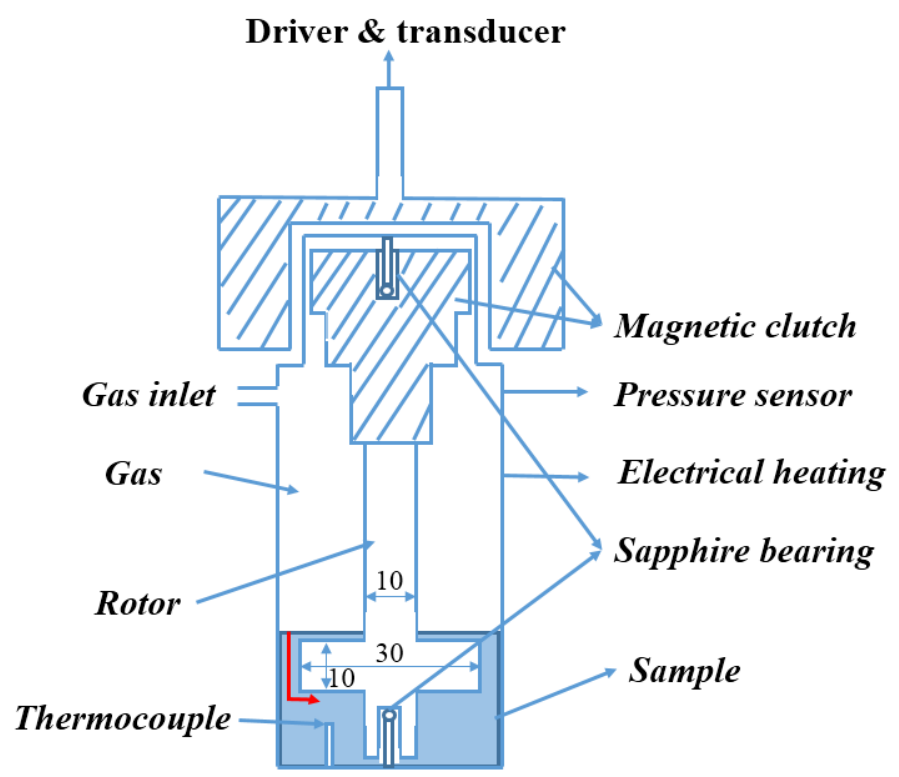

Figure 1. Schematic of high-pressure attachment for the rheometer, which consists of a magnetic clutch, a pressure cell, a rotor and a stator (dimensions in $\mathrm{mm}$ ). 


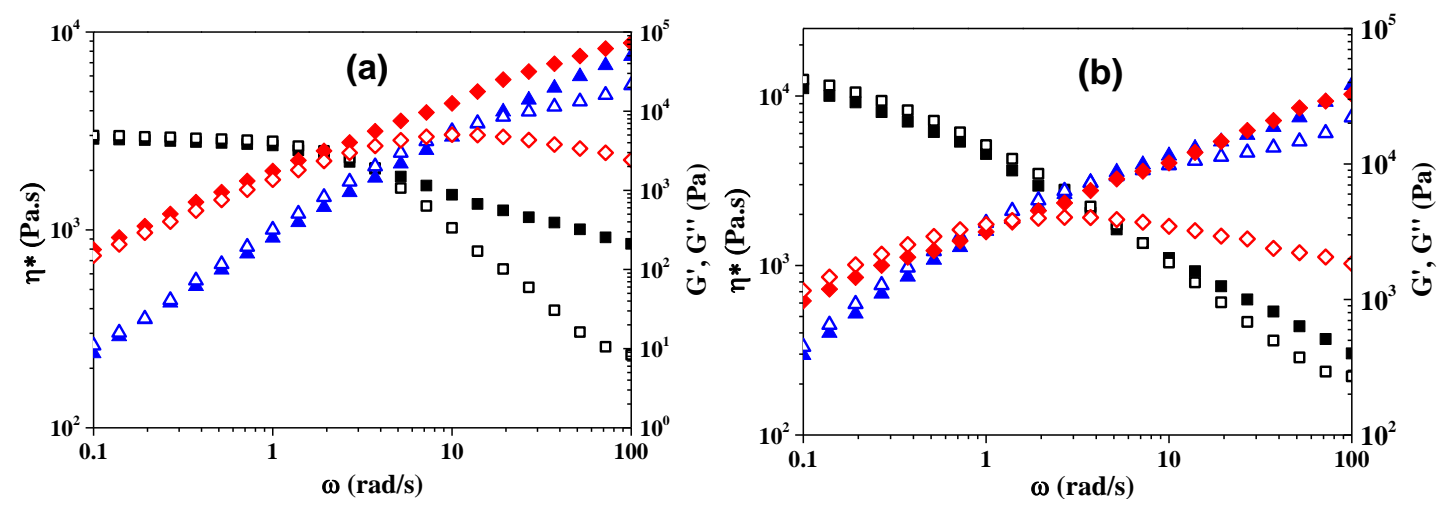

Figure 2. Comparison of the experimental results between the plate geometry (solid interior) and rotor geometry (open interior) configurations of (a) HDPE and (b) LDPE at $150{ }^{\circ} \mathrm{C}$, including $\eta^{*}(\boldsymbol{\bullet}, \square), \mathrm{G}^{\prime}(\boldsymbol{\Delta}, \Delta)$ and $\mathrm{G}^{\prime}(\diamond, \diamond)$. 


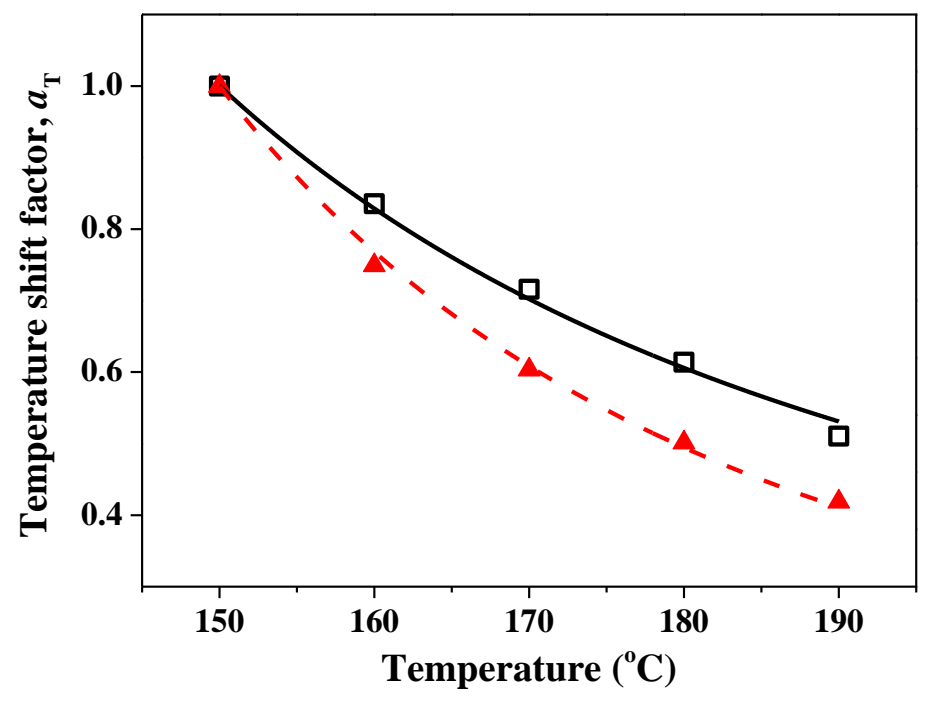

Figure 3. Temperature shift factors of the two polymers and the Arrhenius fitting results. The lines are the model fitting values, and symbols represent the experimental results for $\operatorname{HDPE}(\square,-)$ and $\operatorname{LDPE}(\boldsymbol{\Lambda},---)$. The reference temperature $T_{r}=150{ }^{\circ} \mathrm{C}$, $E_{a, H D P E}=26.63 \pm 0.35 \mathrm{~kJ} / \mathrm{mol}$ and $E_{a, L D P E}=37.52 \pm 1.27 \mathrm{~kJ} / \mathrm{mol}$. 

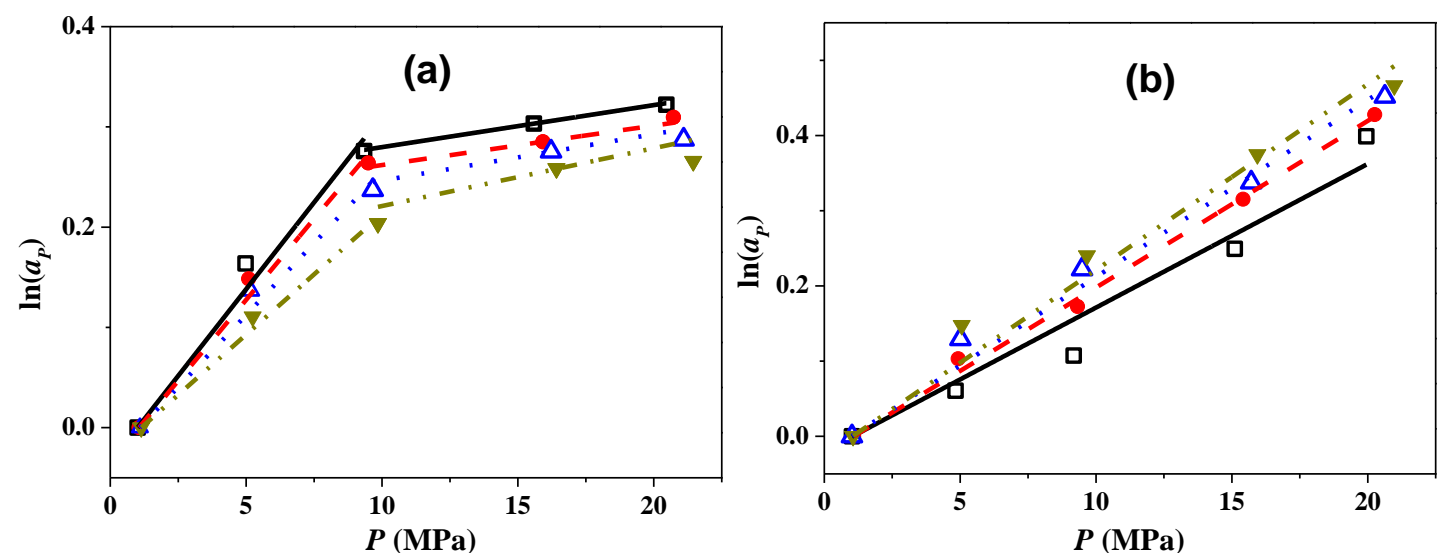

Figure 4. Effect of helium pressure on the pressure shift factors at different temperature. The reference temperature $T_{r}=150{ }^{\circ} \mathrm{C}$, and the reference pressure $P_{r}$ $=1.0 \mathrm{MPa}$. The lines are model fitted values, and symbols are the experimental results for (a) HDPE and (b) LDPE at $150{ }^{\circ} \mathrm{C}(\square,-),, 160{ }^{\circ} \mathrm{C}(\bullet,---), 170{ }^{\circ} \mathrm{C}(\Delta, \cdots)$ and $180{ }^{\circ} \mathrm{C}(\boldsymbol{\nabla},---)$. 


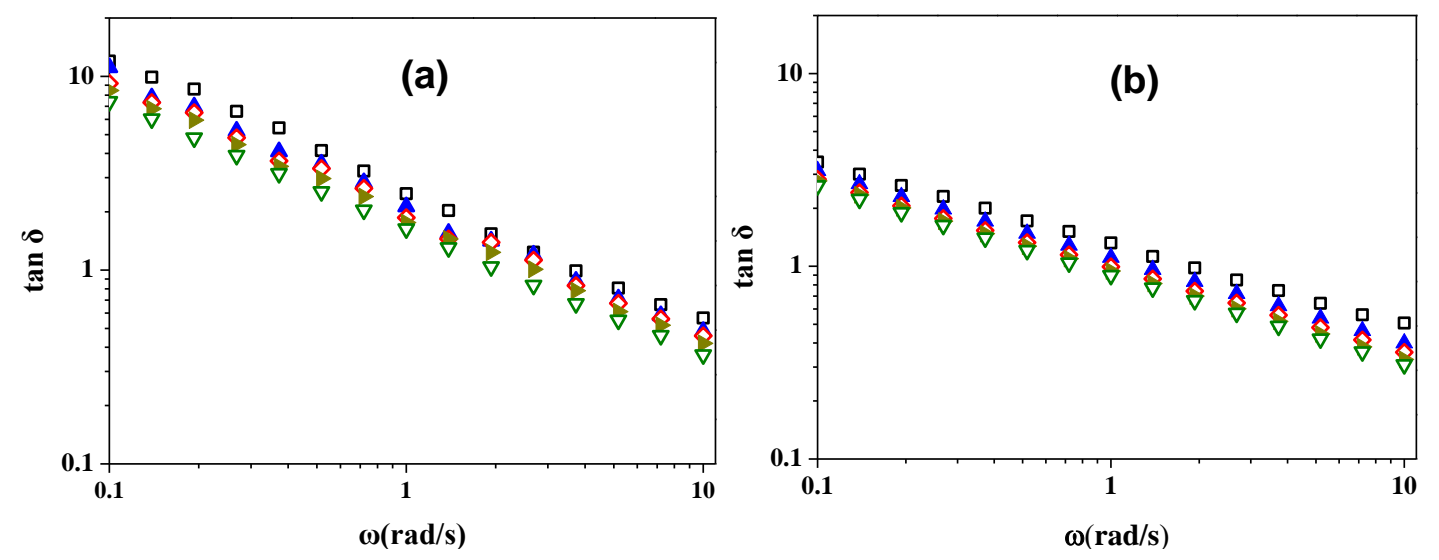

Figure 5. Effect of helium pressure on the loss factors of HDPE and LDPE at $150{ }^{\circ} \mathrm{C}$.

(a) HDPE: $1.01 \mathrm{MPa}(\square), 4.98 \mathrm{MPa}(\boldsymbol{\Delta}), 9.34 \mathrm{MPa}(\diamond), 15.59 \mathrm{MPa}(\triangleright)$, and 20.46 $\mathrm{MPa}(\nabla)$; (b) LDPE: $1.02 \mathrm{MPa}(\square), 5.81 \mathrm{MPa}(\boldsymbol{\Delta}), 10.80 \mathrm{MPa}(\diamond), 15.06 \mathrm{MPa}(\triangleright)$, and $19.61 \mathrm{MPa}(\nabla)$. 

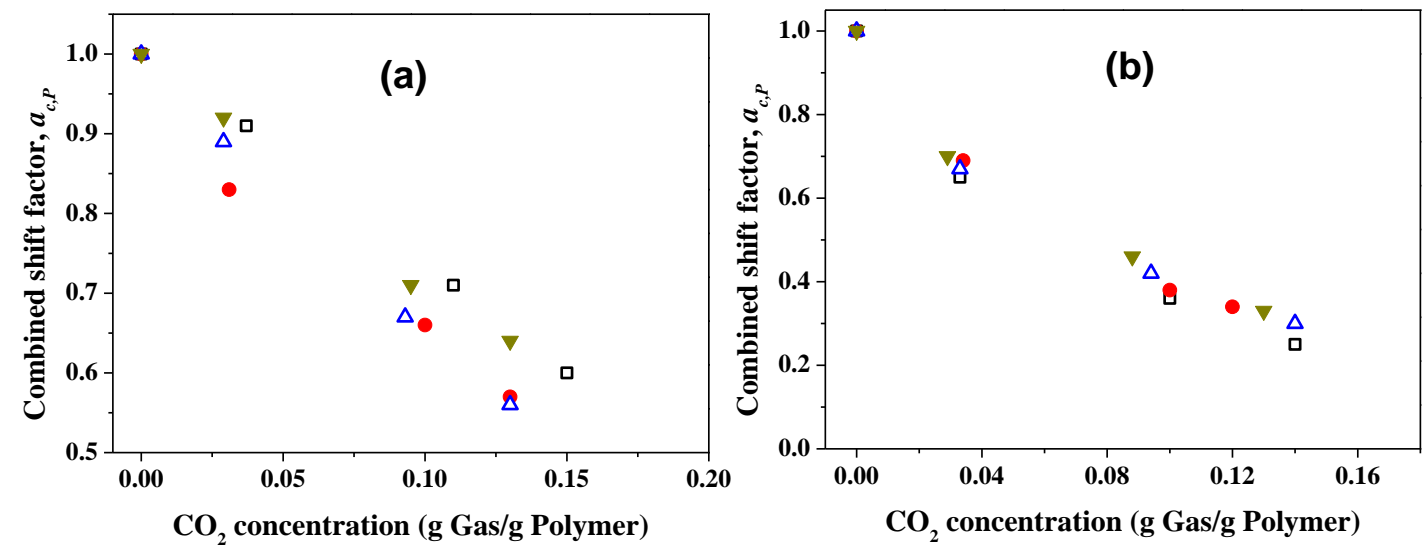

Figure 6. Combined effects of $\mathrm{CO}_{2}$ content and pressure on the shift factors of (a) HDPE and (b) LDPE at different temperatures: $150{ }^{\circ} \mathrm{C}(\square), 160{ }^{\circ} \mathrm{C}(\bullet), 170{ }^{\circ} \mathrm{C}(\Delta)$, and $180{ }^{\circ} \mathrm{C}(\boldsymbol{\nabla})$. 

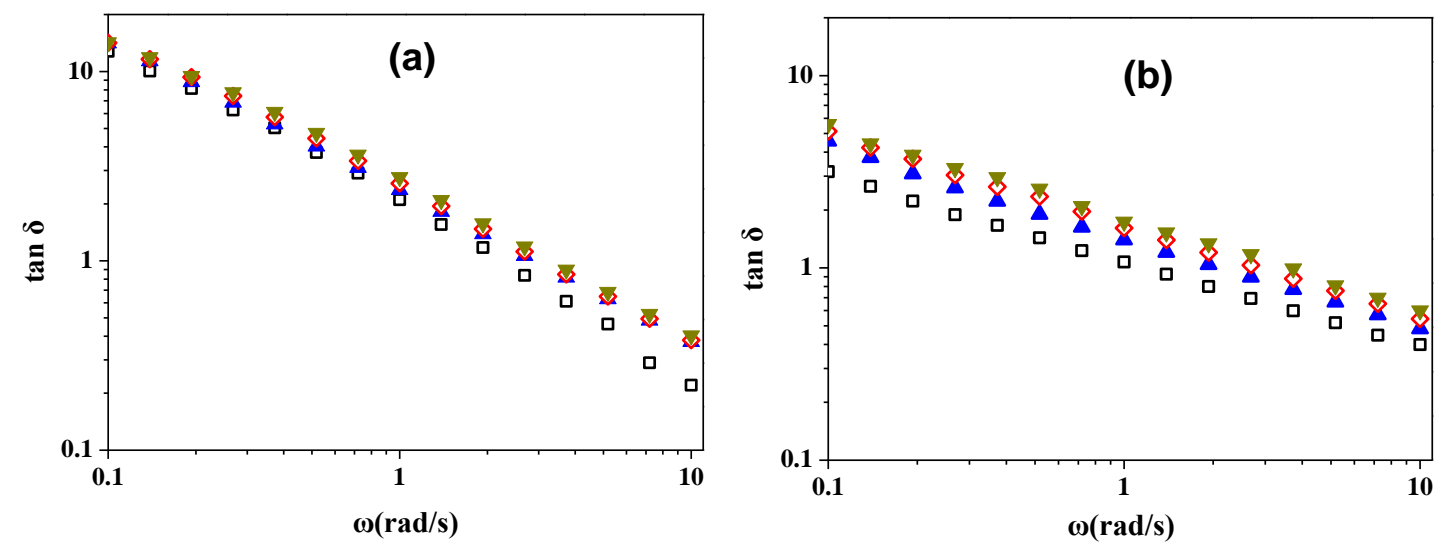

Figure 7. Combined effect of $\mathrm{CO}_{2}$ pressure and concentration on the loss factors of (a) HDPE: $1.07 \mathrm{MPa}(\square), 6.13 \mathrm{MPa}(\boldsymbol{\Delta}), 17.22 \mathrm{MPa}(\diamond), 25.67 \mathrm{MPa}(\boldsymbol{\nabla})$ and $(\mathbf{b}) \mathrm{LDPE}:$ 1.09 $\mathrm{MPa}(\square), 5.36 \mathrm{MPa}(\boldsymbol{\Delta}), 16.56 \mathrm{MPa}(\diamond)$ and $22.77 \mathrm{MPa}(\boldsymbol{\nabla})$ at $150{ }^{\circ} \mathrm{C}$. 

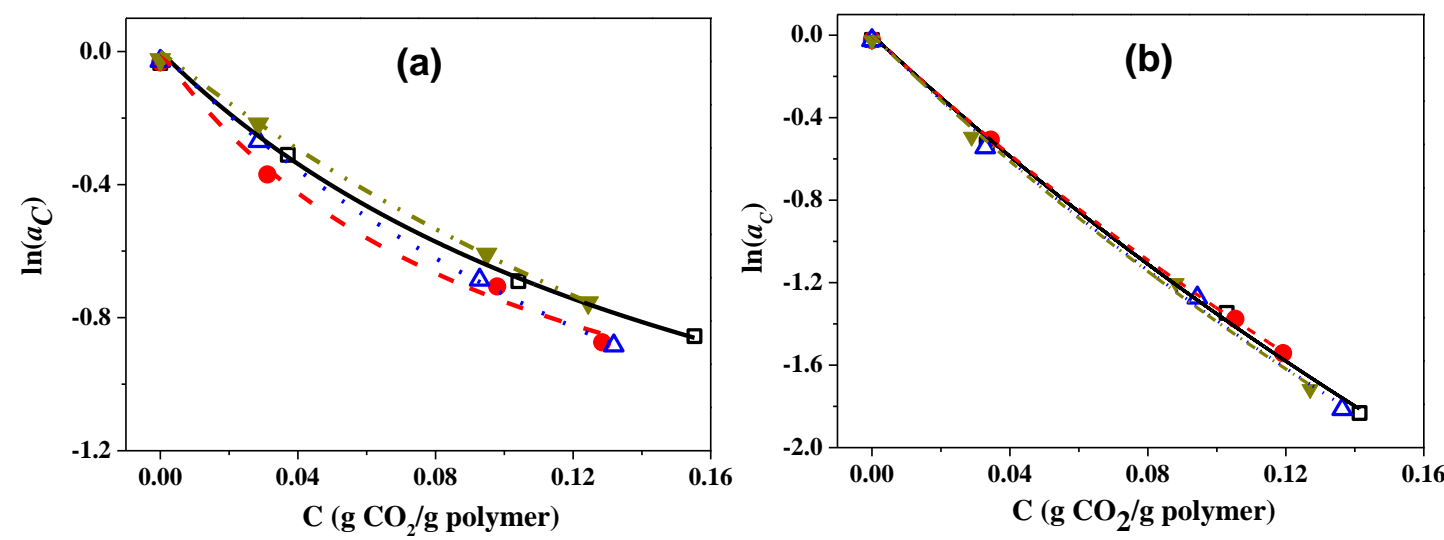

Figure 8. Effect of $\mathrm{CO}_{2}$ concentration on the gas concentration shift factors for (a)

HDPE and (b) LDPE. The lines are model fitted values, and symbols are the experimental results at $150{ }^{\circ} \mathrm{C}(\square,-),, 160{ }^{\circ} \mathrm{C}(\bullet,---), 170{ }^{\circ} \mathrm{C}(\Delta, \cdots)$ and $180{ }^{\circ} \mathrm{C}$ $(\boldsymbol{\nabla},---)$. 


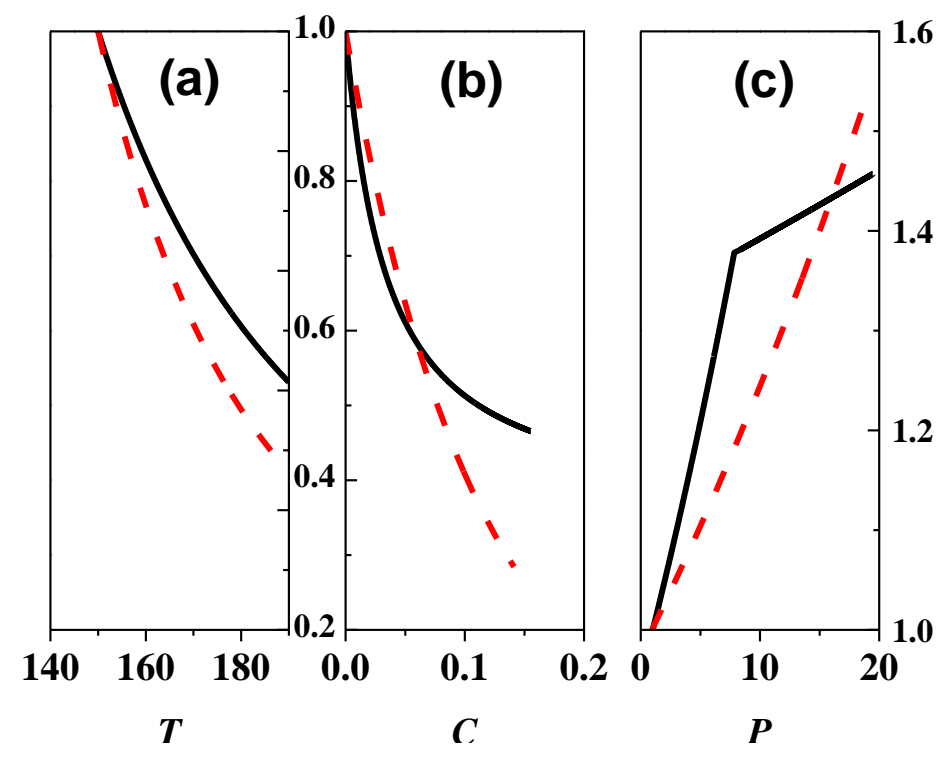

Figure 9. Effect of (a) temperature $\left(\boldsymbol{T},{ }^{\circ} \mathrm{C}\right)$, (b) $\mathrm{CO}_{2}$ concentration $(\boldsymbol{C}, \mathrm{g}$ gas $/ \mathrm{g}$ polymer) and (c) pressure $(\boldsymbol{P}, \mathrm{MPa})$ on the rheological shift factors of HDPE (一) and LDPE (---). 


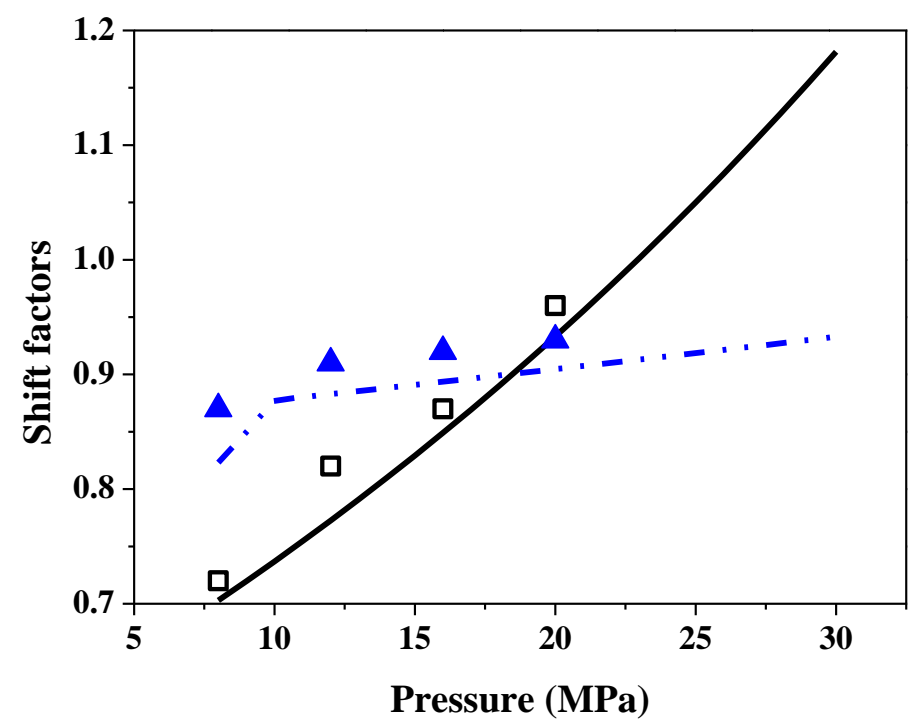

Figure 10. Comparison of experimental results with the model (Eq. (9)) fitting results of HDPE and LDPE. The lines are the model fitting values, and symbols represent the experimental results for $\operatorname{HDPE}(\square,-)$ and $\operatorname{LDPE}(\boldsymbol{\Lambda},---)$. 
Table 1. Molecular parameters and thermal properties of HDPE and LDPE from SEC

\begin{tabular}{lccccc}
\hline & $M_{w}, \mathrm{~g} / \mathrm{mol}$ & $M_{z}, \mathrm{~g} / \mathrm{mol}$ & $M_{w} / M_{n}$ & MI, g/10 min & $\rho^{b}, \mathrm{~g} / \mathrm{cm}^{3}$ \\
\hline HDPE1 $^{a}$ & 94405 & 205300 & 2.78 & 8.0 & 0.83 \\
LDPE1 $^{a}$ & 338996 & $1.67 \mathrm{e}+6$ & 18.45 & 6.5 & 0.83 \\
$\mathrm{HDPE}^{b}$ & 92305 & 193258 & 2.82 & $/$ & $/$ \\
$\mathrm{LDPE}^{b}$ & 300781 & $1.53 \mathrm{e}+6$ & 19.04 & $/$ & $/$ \\
\hline
\end{tabular}

$a$ : 1 represents the raw material, 2 represents the polymer that experiences $\mathrm{CO}_{2}$ saturation at $180{ }^{\circ} \mathrm{C}$ for 38 hours;

$b$ : The density of the melt under high temperature and pressure was determined from the sample calibration process during the solubility measurement using helium. 
Table 2. Calculation of the zero-shear viscosity, relaxation time and Cross exponent for HDPE and LDPE at $150{ }^{\circ} \mathrm{C}$ under different pressures. The reference temperature $T_{r}=150{ }^{\circ} \mathrm{C}$, and the reference pressure $P_{r}=1.0 \mathrm{MPa}$.

\begin{tabular}{|c|c|c|c|c|c|c|c|}
\hline \multirow{2}{*}{$\begin{array}{c}\text { Pressure } \\
(\mathrm{MPa})\end{array}$} & \multicolumn{3}{|c|}{ HDPE } & \multirow{2}{*}{$\begin{array}{l}\text { Pressure } \\
(\mathrm{MPa})\end{array}$} & \multicolumn{3}{|c|}{ LDPE } \\
\hline & $\eta_{0}$ & $\lambda$ & $n$ & & $\eta_{0}$ & $\lambda$ & $n$ \\
\hline 1.0 & 3022 & 0.16 & 0.95 & 1.0 & 17013 & 2.87 & 0.81 \\
\hline 5.0 & 3555 & 0.24 & 0.94 & 4.8 & 18076 & 2.95 & 0.81 \\
\hline 9.4 & 3978 & 0.29 & 0.94 & 9.2 & 18942 & 3.23 & 0.82 \\
\hline 15.6 & 4041 & 0.30 & 0.96 & 15.1 & 21829 & 3.45 & 0.83 \\
\hline 20.5 & 4180 & 0.31 & 0.96 & 19.9 & 27057 & 3.91 & 0.83 \\
\hline
\end{tabular}


Table 3. Pressure coefficients of HDPE and LDPE.

\begin{tabular}{cccc}
\hline \multirow{2}{*}{$\begin{array}{c}c \\
\text { Temperature }\end{array}$} & \multicolumn{2}{c}{ HDPE } & LDPE \\
& $0-10 \mathrm{MPa})$ & $>10 \mathrm{MPa}$ & $0-25 \mathrm{MPa}$ \\
\cline { 2 - 4 } & \multicolumn{3}{c}{$\beta\left(\mathrm{GPa}^{-1}\right)$} \\
\hline 150 & 34.4 & 4.2 & 20.4 \\
160 & 32.3 & 3.9 & 23.6 \\
170 & 28.7 & 4.6 & 25.2 \\
180 & 24.0 & 5.7 & 26.3 \\
\hline
\end{tabular}


Table 4. Fitting parameters for the dependence of viscosity on the temperature, pressure and $\mathrm{CO}_{2}$ concentration of HDPE and LDPE.

\begin{tabular}{ccccc}
\hline & \multicolumn{2}{c}{ HDPE } & \multicolumn{2}{c}{ LDPE } \\
\cline { 2 - 5 } Temperature $\left({ }^{\circ} \mathrm{C}\right)$ & $f$ & $\theta$ & $f$ & $\theta$ \\
\hline $150^{*}$ & 0.08 & 0.25 & 0.10 & 0.15 \\
160 & 0.07 & 0.25 & 0.11 & 0.18 \\
170 & 0.07 & 0.12 & 0.10 & 0.17 \\
180 & 0.07 & 0.13 & 0.11 & 0.19 \\
\hline
\end{tabular}

*: the reference temperature. 


\section{Graphical Abstract}

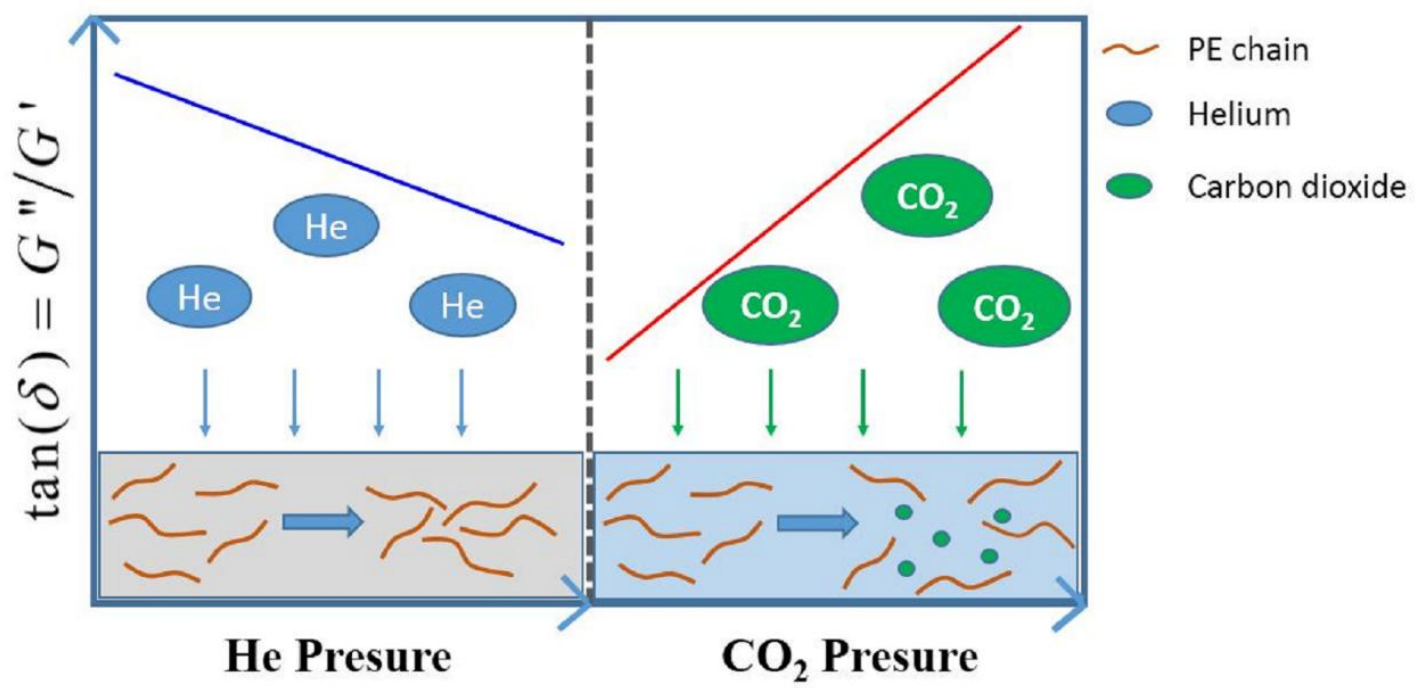

